\title{
Substituição de milho grão inteiro por aveia preta grão no desempenho de cordeiros confinados recebendo dietas com alto grão
}

\section{Replacement of whole corn grain by oat grain on performance of fedlot lambs receiving high grain diets}

\author{
César Aparecido de Araujo Borges ${ }^{1}$; Edson Luis de Azambuja Ribeiro ${ }^{2 *}$; Ivone \\ Yurika Mizubuti²; Leandro das Dores Ferreira da Silva3; Elzânia Sales Pereira ${ }^{4}$; \\ Tiago Galafassi Zarpelon ${ }^{1}$; Camila Constantino ${ }^{5}$; Ricardo Favero ${ }^{6}$
}

\section{Resumo}

Este trabalho teve como objetivo avaliar os efeitos de diferentes níveis de substituição do milho grão inteiro por aveia preta grão $(0,15$ e $30 \%$ base natural), em rações a base de concentrados sobre o consumo de matéria seca e de nutrientes, o desempenho e a viabilidade econômica de ovinos confinados. Foram utilizados 24 ovinos da raça Texel, sendo 12 machos inteiros e 12 fêmeas da mesma idade, com peso médio inicial de 24,0 $\pm 2,8 \mathrm{~kg}$, distribuídos em 12 baias, sendo alojados dois animais de gêneros distintos por baia, e distribuídos em delineamento inteiramente casualizado em três tratamentos experimentais. Os animais receberam as rações experimentais duas vezes ao dia, de modo a permitir sobras de $15 \%$. Os tratamentos não apresentaram diferença estatística para consumo de matéria seca, conversão alimentar, pesos de carcaça quente e fria, rendimentos de carcaça quente e fria, perdas no resfriamento, conformação e acabamento. A crescente inclusão de aveia preta em substituição ao milho inteiro apresentou efeito linear crescente sobre o consumo de proteína bruta, fibra bruta e fibra em detergente neutro e efeito quadrático sobre o consumo de extrato etéreo. A substituição do milho inteiro por aveia em rações sem forragem, em até $30 \%$, pode ser utilizada sem interferir nos resultados de desempenho. A inclusão de $30 \%$ de aveia é a mais indicada, pois proporcionou a maior margem bruta.

Palavras-chave: Amido, confinamento, ovinos, rações

\begin{abstract}
This study aimed to evaluate the effects of different levels of replacement of whole corn grain by oats grain $(0,15$ and $30 \%$ natural base), in rations based in concentrates on dry matter and nutrients intake, performance and economic viability of fedlot lambs. Twenty-four Texel lambs were used, being 12 non castrated males and 12 females; with average weight of $24.0 \pm 2.8 \mathrm{~kg}$. Lambs were housed in 12 pens, being two lambs per pen, and distributed in a completely randomized design into three experimental treatments. The animals received the experimental diets twice a day to allow $15 \%$ surplus. The treatments did not differ significantly for dry matter intake, feed conversion, hot and cold carcass weight, carcass yield, cooling losses, conformation and finishing scores. The increasing inclusion of
\end{abstract}

\footnotetext{
1 Mestres em Ciência Animal, Centro de Ciências Agrárias, Universidade Estadual de Londrina/CCA/UEL, Londrina, PR. E-mail: cesar.borges@pahc.com; tiago.nutron@gmail.com

2 Profs. Drs. do Dept ${ }^{\mathrm{o}}$ de Zootecnia da Universidade Estadual de Londrina, UEL. Pesquisadores do CNPq. E-mail: elar@uel.br; mizubuti@uel.br

3 Prof. Dr. do Dept ${ }^{\circ}$ de Zootecnia, UEL. Londrina, UEL. E-mail:leandro@uel.br

4 Prof $^{\mathrm{a}}$ Dr $^{\mathrm{a}}$ do Dept ${ }^{\mathrm{o}}$ de Zootecnia da Universidade Federal do Ceará, UFC. Pesquisadora do CNPq. E-mail: elzania@hotmail.com

5 Doutoranda em Ciência Animal, CCA/UEL, Londrina, PR. E-mail: caconstantino@hotmail.com

6 Médico Veterinário, UEL, Londrina, PR. E-mail: rfavero@hotmail.com

* Autor para correspondência
} 
oats as a replacement for corn grain showed linear increases in crude protein, crude fiber and neutral detergent fiber consumptions, and quadratic effect on intake of ether extract. The replacement of corn grain by oats grain in diets without roughage, up to $30 \%$, can be used without interfering with the results of growth performance. The inclusion of $30 \%$ of oats is the most suitable, because it provided the highest gross margin.

Key words: Feedlot, rations, sheep, starch

\section{Introdução}

Nos últimos anos, a demanda pela carne de cordeiro tem aumentado significativamente, principalmente nas capitais e grandes cidades do país. Assim, o atendimento a este tipo de público consumidor, passa impreterivelmente pelo confinamento dos cordeiros ainda jovens, com dietas balanceadas e, de densidade energética adequada a obtenção de um produto com qualidade superior e com a padronização necessária (NERES et al., 2005, MURTA et al., 2009).

Entretanto, o confinamento é uma técnica que implica em maior grau de tecnologia e investimentos por parte do produtor rural, visto existir maior necessidade de instalações, maquinário e de pessoal capacitado envolvidos no processo. Um dos maiores entraves à disseminação desta técnica é a produção de volumosos, que demanda área para o plantio, bem como planejamento estratégico antecipado.

Dietas com alto teor de concentrado tornaramse economicamente viáveis, nos últimos anos, em função da elevação no custo de produção de volumosos, redução no preço dos concentrados e ao aumento da oferta de co-produtos da indústria (CERVIERI, 2009).

De acordo com Bolzan et al. (2007), para os pequenos ruminantes, a oferta de grão inteiro pode ser realizada, visto a maior eficiência destes animais em ruminar, mastigar e consequentemente produzir saliva. Na Argentina, o uso de grão inteiro de milho tem se disseminado muito e a conversão alimentar alcançada com grão inteiro é similar ou levemente inferior ( 8 a 10\%) às alcançadas com grão moído ou amassado seco (KATSUKI, 2009).

Tem ocorrido um excedente de produção de aveia, principalmente na região sul, onde esta é cultivada com o intuito de produção de sementes e grãos, bem como para servir como cobertura do solo e posterior fonte de palhada para o plantio direto das culturas de verão (FATURI et al., 2003).

A utilização da aveia preta sem nenhum tipo de processamento do grão é muito contestada, principalmente pelo fato da aveia preta possuir o pericarpo que envolve o endosperma e o gérmen mais fibroso do que a aveia branca, o que a torna mais resistente à degradação pelos microorganismos ruminais (RESTLE; FATURI; PASCOAL, 2001).

Entretanto, Mathison (1996) não observou diferença para o tipo de processamento dado a aveia, concluindo ser melhor sua utilização de forma não processada (inteira), devido ao alto custo para sua moagem, ocasionado pela dificuldade de trituração.

Objetivou-se com este trabalho avaliar, em cordeiros, o efeito de diferentes níveis de substituição do milho grão inteiro por aveia preta grão não processada, sobre os índices zootécnicos de desempenho, consumo de nutrientes e viabilidade econômica.

\section{Material e Métodos}

O experimento foi conduzido na Fazenda Escola da Universidade Estadual de Londrina no período de 05 de setembro a 16 de outubro de 2009. Foram utilizados 24 ovinos da raça Texel, sendo 12 machos inteiros e 12 fêmeas da mesma idade, com peso médio inicial de $24 \mathrm{~kg}$, distribuídos em 12 baias, sendo alojados dois animais de gêneros distintos por baia. As baias continham área de 2,5 $\mathrm{m}^{2}$, piso de concreto coberto com cama de cepilho 
de madeira, bebedouro e cocho de alimentação com disponibilidade de $20 \mathrm{~cm} /$ animal.

Os animais passaram por um período de adaptação as instalações e ao alimento de sete dias. Neste período os cordeiros receberam feno de Tifton (Cynodon spp.) a vontade, e quantidades diárias crescentes das rações experimentais.

Os alimentos, nas suas respectivas proporções, foram fornecidos à vontade duas vezes ao dia, às 7:30 e às 17:30 horas, sendo que as sobras foram registradas e pesadas diariamente para a determinação do consumo diário. A quantidade de ração fornecida foi calculada de modo a permitir aproximadamente $15 \%$ de sobras, enquanto o fornecimento de água foi à vontade.

As rações foram compostas, utilizando-se os seguintes ingredientes: grão inteiro de milho, grão inteiro de aveia preta e concentrado protéico comercial (farelo de soja, uréia, núcleo mineralvitamínico e aditivo promotor de crescimento). As proporções dos ingredientes e a composição química das rações encontram-se na Tabela 1.

Tabela 1. Proporções (\%) dos ingredientes das rações experimentais e composição bromatológica das rações.

\begin{tabular}{lccc}
\hline & \multicolumn{3}{c}{$\begin{array}{c}\text { Rações experimentais } \\
\text { (Níveis de substituição) }\end{array}$} \\
\cline { 2 - 4 } Ingredientes & $\mathbf{T 1}$ & $\mathbf{T 2}$ & $\mathbf{T 3}$ \\
& $\mathbf{( 0 \% )}$ & $\mathbf{( 1 5 \% )}$ & $\mathbf{( 3 0 \% )}$ \\
\hline Milho - Grão Inteiro & 84,75 & 69,83 & 54,91 \\
Aveia Preta - Grão inteiro & 0 & 14,92 & 29,84 \\
Concentrado Protéico, Mineral e Vitamínico & 15,25 & 15,25 & 15,25 \\
Total & 100 & 100 & 100 \\
\hline Composição Bromatológica (\% na MS) & & & \\
\hline Materia Seca & 88,95 & 89,55 & 88,96 \\
Nutrientes Digestíveis Totais & 78,97 & 77,67 & 77,21 \\
Proteína Bruta & 12,18 & 13,73 & 16,72 \\
Extrato Etéreo & 3,82 & 3,60 & 4,12 \\
Fibra em Detergente Neutro & 21,05 & 30,23 & 28,96 \\
Amido & 60,15 & 57,5 & 54,79 \\
Matéria mineral & 3,61 & 3,68 & 3,69 \\
Monensina Sódica ${ }^{2}$ (ppm) & 25,41 & 25,41 & 25,41 \\
\hline
\end{tabular}

${ }^{1}$ Composição: Nutrientes digestíveis totais (\% na MS), 65,40; Proteína bruta (\% na MS), 41,83; Extrato etéreo (\% na MS), 4,65; Fibra em detergente neutro ( $\%$ na MS), 13,30; Fibra em detergente ácido ( $\%$ na MS), 7,65; Matéria mineral (\% na MS), 27,22; Vitamina A (UI/kg), 33.330,00; Vitamina D3 (UI/kg), 2.220,00; Vitamina E (UI/kg), 138,88; Cálcio (\% na MS), 5,61; Fósforo ( $\%$ na MS), 1,11; Enxofre (\% na MS), 5,00; Sódio ( $\%$ na MS), 9,44; Cloro ( $\%$ na MS), 14,77; Manganês (mg/kg), 277,7; Cobre (mg/kg), 91,11; Iodo (mg/kg), 4,97; Zinco (mg/kg), 360,00; Cobalto (mg/kg), 4,97; Selênio (mg/kg), 1,53; Monensina sódica (mg/kg MS), 166,66.

${ }^{2}$ Calculado com base nos níveis de garantia do concentrado protéico, mineral e vitamínico multiplicado pela sua inclusão na ração.

Fonte: Elaboração dos autores.

Semanalmente foram colhidas amostras As amostras semanais correspondentes a cada do alimento oferecido, bem como das sobras. um dos períodos de 14 dias foram agrupadas 
proporcionalmente, constituindo-se as amostras compostas. As amostras foram secas em estufa a $55^{\circ} \mathrm{C}$ por 48 horas e moídas para análise.

As análises bromatológicas foram processadas no Laboratório de Nutrição Animal da Universidade Estadual de Londrina. As determinações de matéria seca (MS), matéria orgânica (MO), proteína bruta (PB), extrato etéreo (EE), fibra em detergente neutro $(\mathrm{FDN})$, fibra bruta $(\mathrm{FB})$ e matéria mineral $(\mathrm{MM})$ foram realizadas conforme metodologias citadas por Mizubuti et al. (2009). Os nutrientes digestíveis totais (NDT) foram estimados pela equação sugerida pelo NRC (1996), sendo:

$\mathrm{NDT}=40,26+(0,1969 \quad \mathrm{x} \quad \mathrm{PB})+(0,4228 \quad \mathrm{x}$ $\mathrm{ENN})+(1,19 \times \mathrm{EE})-(0,1379 \times \mathrm{FB})$

As pesagens dos animais foram realizadas ao inicio do experimento e ao final de cada período experimental de 14 dias, após jejum de sólidos de 12 horas, completando três períodos experimentais. A partir desses dados foram calculados o ganho médio diário (GMD), a matéria seca ingerida (em kg; como percentagem do peso vivo; por unidade de peso metabólico ((peso corporal em $\left.\mathrm{kg})^{0,75}\right)$ ), e a conversão alimentar (CA) (matéria seca ingerida /ganho médio diário).

Após 42 dias de experimento os animais foram submetidos ao manejo pré-abate, com pesagem após jejum de sólidos de 12 horas. O abate foi realizado em um frigorífico comercial localizado no distrito de São Martinho, cidade de Rolândia, a $45 \mathrm{~km}$ da cidade de Londrina, seguindo a legislação de abate (BRASIL, 2000).

Ao término do abate, foram anotados os pesos de carcaça quente. As carcaças foram identificadas e mantidas em câmara fria por 24 horas à temperatura de $2^{\circ} \mathrm{C}$, sendo pesadas para obtenção do peso de carcaça fria. Em função destes pesos foram obtidos os rendimentos de carcaça quente e fria e a perda de umidade no resfriamento.

Foi realizada a avaliação de conformação, que indica o grau de musculosidade da carcaça (valores de 1 - côncavo a 5 - convexo), e acabamento, que avalia a quantidade de gordura subcutânea na carcaça (valores de 1 - gordura de cobertura ausente a 4 - gordura de cobertura abundante) utilizando-se padrões fotográficos (CAÑEQUE; SAÑUDO, 2000).

Para se efetuar a análise econômica da alimentação oferecida no experimento, foram considerados os preços de mercado obtidos para os ingredientes das rações, para a carcaça e o peso vivo de cordeiros. De posse do custo de cada ração e do consumo de matéria seca das mesmas, foi calculado o resultado econômico proporcionado por ração.

Os resultados foram interpretados estatisticamente por meio de análises de variância e regressão, utilizando-se o pacote estatístico SAS (1999).

\section{Resultado e Discussão}

Os consumos de matéria seca (CMS), expressos em $\mathrm{kg}$ por dia, porcentagem do peso vivo (\%PV) e $\mathrm{kg}$ por unidade de tamanho metabólico $(\mathrm{kg} /$ $\left.\mathrm{kg}^{0,75}\right)$, não apresentaram diferença estatística $(\mathrm{P}>0,05)$ nos diferentes níveis de inclusão de aveia (Tabela 2).

O CMS (\%PV) em média para os três tratamentos foi de 3,20\%. Resultado este que vem de acordo com os $3,55 \%$ obtidos por Urano et al. (2006) e os obtidos em trabalho semelhante por Zarpelon (2010), que encontrou média de 3,67\%. Entretanto pode ser considerado relativamente baixo quando comparado ao consumo predito pelo NRC (2007) que é de $4,15 \%$ do PV para cordeiros com peso médio de $30 \mathrm{~kg}$ e ganho médio diário de $300 \mathrm{~g} /$ dia. 
Tabela 2. Consumo, por baia, de matéria seca (MS) e nutrientes em cordeiros alimentados com diferentes níveis de substituição do grão de milho inteiro por grão de aveia.

\begin{tabular}{|c|c|c|c|c|c|c|}
\hline \multirow[b]{2}{*}{ Consumo } & \multicolumn{4}{|c|}{ Tratamentos } & \multirow[b]{2}{*}{$\mathbf{R}^{2}$} & \multirow[b]{2}{*}{ Regressão* } \\
\hline & $\begin{array}{c}\text { T1 } \\
(0 \%)\end{array}$ & $\begin{array}{c}\mathrm{T} 2 \\
(15 \%)\end{array}$ & $\begin{array}{c}\text { T3 } \\
(\mathbf{3 0} \%)\end{array}$ & CV $(\%)$ & & \\
\hline$\overline{\mathrm{MS}}(\mathrm{kg} / \mathrm{dia})$ & 1,86 & 1,90 & 2,12 & 12,69 & - & $\tilde{y}=1,96$ \\
\hline MS (\%PV) & 3,21 & 3,04 & 3,32 & 10,61 & - & $\tilde{y}=3,20$ \\
\hline MS (kg/PV0,75) & 0,099 & 0,086 & 0,094 & 11,10 & - & $\tilde{y}=0,089$ \\
\hline PB (kg/dia) & 0,20 & 0,25 & 0,36 & 13,45 & 0,81 & $\hat{y}=0,20362+0,001984 x$ \\
\hline PB (\%PV) & 0,35 & 0,41 & 0,57 & 11,47 & 0,81 & $\hat{\mathrm{y}}=0,335+0,00735 \mathrm{x}$ \\
\hline EE (kg/dia) & 0,074 & 0,069 & 0,089 & 12,72 & 0,51 & $\begin{aligned} \hat{y}=0,074005-0,00112158 x \\
+0,00005491 x^{2}\end{aligned}$ \\
\hline $\mathrm{EE}(\% \mathrm{PV})$ & 0,12 & 0,11 & 0,14 & 10,64 & 0,51 & $\begin{array}{l}\hat{y}=0,12773-0,00261 x \\
+0,00010134 x 2\end{array}$ \\
\hline FDN (kg/dia) & 0,37 & 0,58 & 0,62 & 12,60 & 0,79 & $\begin{array}{l}\hat{y}=0,37276+ \\
0,02020125 x\end{array}$ \\
\hline FDN (\%PV) & 0,64 & 0,94 & 0,97 & 10,63 & 0,78 & $\begin{array}{l}\hat{y}=0,64310+0,02844 x \\
-0,00057449 x^{2}\end{array}$ \\
\hline NDT (kg/dia) & 1,48 & 1,47 & 1,64 & 12,62 & - & $\tilde{y}=1,53$ \\
\hline NDT (\%PV) & 2,56 & 2,36 & 2,57 & 10,54 & - & $\tilde{y}=2,50$ \\
\hline MM (kg/dia) & 0,054 & 0,072 & 0,074 & 13,56 & 0,56 & $\begin{array}{l}\hat{y}=0,0542375+ \\
0,00166492 x\end{array}$ \\
\hline $\mathrm{MM}(\% \mathrm{PV})$ & 0,09 & 0,11 & 0,11 & 11,55 & 0,48 & $\tilde{y}=0,10$ \\
\hline FB (kg/dia) & 0,075 & 0,110 & 0,124 & 12,33 & 0,78 & $\begin{array}{l}\hat{y}=0,0747375+ \\
0,00304433 x\end{array}$ \\
\hline $\mathrm{FB}(\% \mathrm{PV})$ & 0,12 & 0,17 & 0,19 & 10,35 & 0,77 & $\hat{y}=0,12898+0,00409 x$ \\
\hline
\end{tabular}

MS: Matéria seca; MM: Matéria Mineral; PB: Proteína Bruta; EE: Extrato Etéreo; FB: Fibra Bruta; FDN: Fibra em Detergente Neutro; NDT: Nutrientes Digestíveis Totais; * $(\mathrm{P}<0,05)$.

Fonte: Elaboração dos autores.

Mertens (1994) afirmou que com dietas de elevada densidade energética, conforme o presente trabalho (valores de NDT de 78,97; 77,67 e 77,21\%, respectivamente, para os tratamentos 1,2 e 3 ), o consumo é limitado pela demanda energética e não pela limitação física, ou seja, os animais atenderam as suas exigências de energia com um menor consumo relativo ao peso vivo.

$\mathrm{O}$ consumo de $\mathrm{PB}$ em $\mathrm{kg} / \mathrm{dia}$ e \%PV apresentou efeito linear crescente $(\mathrm{P}<0,05)$. Apesar do consumo de MS não ter apresentado diferenças estatísticas, este maior consumo de PB é coerente com os tratamentos apresentados, visto que a aveia possui maior concentração protéica que o milho, o que consequentemente proporciona maior nível protéico para as dietas com a inclusão de aveia, conforme pode ser observado na Tabela 1. Esse maior consumo de PB não refletiu em diferenças estatísticas para as variáveis de desempenho avaliadas no presente trabalho.

Os resultados de consumo de extrato etéreo apresentaram diferença estatística $(\mathrm{P}>0,05) \mathrm{e}$ comportamento quadrático (Tabela 2). Esses consumos refletem a composição das rações 
experimentais, onde o tratamento com $15 \%$ de substituição apresentou o menor teor de extrato etéreo. Ao se derivar as equações de regressão verificou-se que o consumo mínimo de $\mathrm{EE}$, em g/ dia e $\%$ do peso vivo, seria respectivamente com os níveis de 20,43\% e 25,75\% de inclusão de aveia. Apesar dos valores de EE serem utilizados para o cálculo dos nutrientes digestíveis totais, este não interferiu no consumo de NDT, que não diferiu estatisticamente para os tratamentos $(\mathrm{P}>0,05)$.
Isto por sua vez, explica a semelhança observada no desempenho animal produzido pelas rações experimentais (Tabela 3). Mesmo assim, estes dados corroboram para a confirmação da limitação do consumo pelo valor energético das dietas, visto que o consumo médio de NDT observado nos três tratamentos foi muito superior $(1532,8 \mathrm{~g} / \mathrm{dia})$ ao recomendado pelo NRC (2007) que é de $990 \mathrm{~g}$ de NDT/dia para animais de $30 \mathrm{~kg}$ ganhando $300 \mathrm{~g} / \mathrm{dia}$.

Tabela 3. Características, individuais, de desempenho e de carcaça de cordeiros alimentados com diferentes níveis de substituição do grão de milho inteiro por grão de aveia.

\begin{tabular}{|c|c|c|c|c|c|c|}
\hline \multirow[b]{3}{*}{ Parâmetros } & \multicolumn{3}{|c|}{ Rações experimentais } & \multirow{2}{*}{\multicolumn{2}{|c|}{ Sexo }} & \multirow[b]{3}{*}{ CV $(\%)$} \\
\hline & \multicolumn{3}{|c|}{ Níveis de substituição } & & & \\
\hline & T1 (0\%) & T2 (15\%) & T3 (30\%) & $\mathbf{M}$ & $\mathbf{F}$ & \\
\hline PVI (kg) & 22,40 & 24,11 & 24,40 & 23,17 & 24,10 & 11,87 \\
\hline PVF (kg) & 33,62 & 35,25 & 37,53 & 36,18 & 34,75 & 10,61 \\
\hline GPMD (g/dia) & 267 & 265 & 312 & $309 a$ & $253 b$ & 22,18 \\
\hline CA (kg MS/kg PV) & 3,52 & 3,63 & 3,39 & - & - & 11,21 \\
\hline PCQ (Kg) & 17,57 & 18,55 & 19,00 & 18,65 & 18,09 & 10,80 \\
\hline $\mathrm{PCF}(\mathrm{Kg})$ & 16,99 & 17,90 & 18,35 & 18,01 & 17,49 & 10,93 \\
\hline RCQ (\%) & 52,33 & 52,56 & 50,70 & 51,57 & 52,14 & 4,13 \\
\hline $\mathrm{RCF}(\%)$ & 50,59 & 50,70 & 48,97 & 49,77 & 50,40 & 4,20 \\
\hline PR (\%) & 3,31 & 3,52 & 3,41 & $3,50 \mathrm{a}$ & $3,33 b$ & 19,35 \\
\hline CONF & 2,75 & 2,88 & 2,75 & 2,92 & 2,67 & 26,94 \\
\hline $\mathrm{ACAB}$ & 3,25 & 3,38 & 3,38 & 3,25 & 3,41 & 17,63 \\
\hline
\end{tabular}

PVI: peso vivo inicial; PVF: peso vivo final; GPMD: ganho de peso médio diário; CA: conversão alimentar; PCQ: peso de carcaça quente; PCF: peso de carcaça fria; RCQ: rendimento de carcaça quente; RCF: rendimento carcaça fria; PR: perdas por resfriamento, CONF: conformação, $\mathrm{ACAB}$ : acabamento. Médias seguidas de letras diferentes nas linhas diferem $(\mathrm{P}<0,05)$.

Fonte: Elaboração dos autores.

A crescente inclusão de aveia em substituição ao grão de milho inteiro apresentou efeito linear crescente $(\mathrm{P}<0,05)$ sobre o consumo de FDN $(\mathrm{kg} /$ dia) e FB $(\mathrm{kg} /$ dia e $\% \mathrm{PV})$, onde os tratamentos com 15 e $30 \%$ de inclusão de aveia apresentaram maiores médias do que o tratamento sem adição deste cereal. Já o consumo de FDN (\%PV), apresentou efeito quadrático. Ao se substituir na equação de regressão, encontrou-se que o máximo consumo de FDN (\%PV), ocorreria com o nível de inclusão de $24,73 \%$ de aveia. Resultados estes esperados, devido à maior quantidade de FDN nas dietas onde a aveia esteve presente.

De acordo com Faturi et al. (2003), pelo fato de possuir grande quantidade de casca, a aveia seria capaz de proporcionar uma melhor adequação da microflora ruminal no período de adaptação as dietas a base de grãos. Outro fator positivo para as 
dietas com aveia nesta fase de transição é o fato de possuírem uma menor concentração de carboidratos não estruturais, basicamente amido que, segundo Vasconcelos e Galyean (2008), com o consumo excessivo podem levar a queda no $\mathrm{pH}$ ruminal, resultante da elevação de glicose livre e conseqüente aumento da produção de ácido láctico, podendo levar a um quadro de acidose láctica ruminal.

Entretanto, este maior consumo de FDN e a menor concentração de amido da dieta, não refletiram nos resultados de desempenho dos animais, que não apresentaram diferenças $(\mathrm{P}>0,05)$ para nenhum dos parâmetros analisados (Tabela 3).

Não houve efeito $(\mathrm{P}>0,05)$ entre os tratamentos, pelo fato do grão de milho inteiro ser capaz de gerar estímulo suficiente para a ruminação, permitindo eliminar a necessidade de fibra longa em rações de alto teor de grão (PORDOMINGO et al., 2002), atendendo assim as necessidades mínimas para uma boa saúde do rúmen. Segundo Anderson, Merrill e Klopfenstein (1988), nas rações experimentais em que o milho inteiro realiza a função mecânica da fibra, considera-se que o FDN tenha efetividade de $100 \%$.

O ganho de peso foi satisfatório, obtendo média para os três tratamentos de $282 \mathrm{~g} /$ dia. Resultados semelhantes foram encontrados por Zarpelon (2010), que ao avaliar o uso de rações a base de grão de milho inteiro, obteve ganhos de $273 \mathrm{~g} /$ dia. Resultados semelhantes também foram obtidos por Urano et al. (2006), que ao alimentarem cordeiros em regime de confinamento com teores crescentes de grão de soja, obtiveram ganho de peso de 277 g/ dia.

Os resultados de conversão alimentar $(\mathrm{kg}$ de $\mathrm{MS} / \mathrm{kg}$ de peso vivo) também não diferiram ( $\mathrm{P}>0,05)$, entretanto, a média obtida de 3,52 pode ser considerada um excelente resultado, sendo semelhante ao encontrado por Urano et al. (2006), que obtiveram conversão alimentar média de 3,6, os quais foram melhores que os encontrados por outros autores (SIQUEIRA; SIMÕES, FERNANDES,
2001; FURUSHO-GARCIA et al., 2004; CUNHA et al., 2008) ao trabalharem com cordeiros confinados.

Não foram observadas diferenças entre os tratamentos para peso de carcaça quente, peso de carcaça fria, rendimento carcaça quente, rendimento de carcaça fria e perda no resfriamento. Resultados que condizem com os encontrados por Zarpelon (2010), que avaliou os parâmetros, em cordeiros confinados com dietas contendo milho inteiro com diferentes inclusões de casca de soja.

Na Tabela 3 estão apresentados os valores da avaliação subjetiva de conformação $(\mathrm{P}>0,05)$, que indica que todos os animais estavam no padrão 2 (carcaças retilíneas com boa cobertura muscular), e para a avaliação de acabamento $(\mathrm{P}>0,05)$ os animais se encontravam no padrão 3 (boa cobertura de gordura com pequenas porções de músculo aparente).

Segundo Rodrigues et al. (2008), o rendimento de carcaça quente (RCQ) é uma informação importante, pois representa a rentabilidade da porção comestível. O rendimento médio de carcaça apresentado de $51,86 \%$ é muito bom e superior aos encontrados em diversos trabalhos com cordeiros confinados (RODRIGUES et. al., 2008; PIOLA JUNIOR et al., 2009). Entre outros fatores, o RC pode ter sido influenciado pelo baixo peso do conteúdo gastrintestinal devido à ausência de volumoso nas dietas.

A perda no resfriamento (PR) é um parâmetro que indica a perda de peso da carcaça, ocasionada pelo acondicionamento na câmara fria dos frigoríficos e geralmente esta variável está inversamente correlacionada à espessura de gordura (RODRIGUES et al., 2008). O valor médio de PR, obtido para os três tratamentos foi de $3,42 \%$, superior aos 2,4\% encontrado por Rodrigues et al. (2008) e inferior ao valor de 4,3\% obtido por Furusho-Garcia et al. (2004) e Siqueira, Simões e Fernandes, (2001).

Aliado ao confinamento o sexo é um dos fatores mais importantes que se dispõe para a obtenção de 
bons ganhos de peso, por afetar a velocidade de crescimento e a deposição dos distintos tecidos do corpo dos animais (CARVALHO et al., 1999).

Ao avaliarem o desempenho de cordeiros machos inteiros, machos castrados e fêmeas em confinamento, Carvalho et al. (1999) não encontraram diferença significativa para as variáveis estudadas, entretanto, argumentam que possivelmente a superioridade dos machos não se pronunciou devido a idade muito jovem ao abate. Resultados estes diferentes dos observados no presente trabalho, onde houve efeito do sexo sobre o parâmetro ganho de peso diário, sendo os machos superiores as fêmeas, obtendo respectivamente média de $310 \mathrm{~g}$ contra $254 \mathrm{~g}$. Resultados que condizem com os obtidos por Cunha et al. (2001), que observaram diferenças significativas entre os sexos para ganho de peso diário de cordeiros Suffolk confinados, obtendo respectivamente para machos e fêmeas $301 \mathrm{~g}$ e $252 \mathrm{~g}$./dia.

Crouse et al. (1981), relataram que o desempenho superior obtido pelos machos em comparação as fêmeas se deve ao hormônio anabólico testosterona produzido pelos machos e, que quanto maior o nível da alimentação oferecida, maiores são as diferenças observadas entre machos e fêmeas.

A influência da inclusão de diferentes níveis de aveia sobre o custo/kg de ganho de PV, receita bruta e margem bruta por animal encontra-se na Tabela 4. Para o cálculo foi atribuído o valor de $\mathrm{R} \$ 250 /$ tonelada de matéria natural ao milho, $\mathrm{R} \$ 230 /$ tonelada de matéria natural a aveia e $\mathrm{R} \$ 1400 /$ tonelada do pellet protéico, vitamínico e mineral.

Tabela 4. Efeito dos níveis de substituição do milho inteiro por aveia grão em rações à base de concentrados sobre o custo $(\mathrm{R} \$$ ) por quilograma de ganho de peso e Margem Bruta (R $\$$ animal).

\begin{tabular}{lccc}
\hline & \multicolumn{2}{c}{ Rações experimentais (Níveis de substituição) } \\
\hline Item & T1 (0\%) & T2 (15\%) & T3 (30\%) \\
\hline${ }^{1}$ Custo/animal magro, R\$ & 67,20 & 72,34 & 73,20 \\
Custo/kg de MS da ração, R\$ & 0,47 & 0,47 & 0,47 \\
${ }^{2}$ Custo/kg PV engordado no confinamento, R\$ & 1,67 & 1,70 & 1,59 \\
${ }^{3}$ Custo de Alimentação/Animal & & & \\
no confinamento, R $\$$ & 18,78 & 18,95 & 20,90 \\
${ }^{4}$ Custo de Alimentação/animal e aquisição & & & \\
de cordeiro magro, R\$ & 85,98 & 91,29 & 94,10 \\
${ }^{5}$ Receita Bruta confinamento, R \$/animal & 140,60 & 148,45 & 152,00 \\
${ }^{6}$ Margem Bruta confinamento, R $\$$ & 54,62 & 57,16 & 57,90 \\
\hline
\end{tabular}

${ }^{1}$ Considerou-se um custo de $\mathrm{R} \$ 3,00 / \mathrm{Kg}$ vivo; ${ }^{2}$ Produto da conversão alimentar pelo custo/Kg de MS

${ }^{3}$ Produto do item 2 pela diferença entre peso vivo inicial e peso vivo final

${ }^{4}$ Soma dos itens 1 e 3 ; ${ }_{5}$ Considerou-se $\mathrm{R} \$ 8,00 / \mathrm{Kg}$ de carcaça

${ }^{6}$ Diferença entre a receita bruta e o custo de alimentação e de aquisição do cordeiro magro

Fonte: Elaboração dos autores.

Apesar da similaridade nos parâmetros de ganho de peso, conversão alimentar e características de carcaça avaliadas no presente trabalho, a superioridade observada para a ração com $30 \%$ de aveia em CA e GPMD, se demonstrou na avaliação da margem bruta deixada pelas rações experimentais, onde o respectivo tratamento foi o mais viável economicamente, deixando uma margem bruta de R\$57,90/cabeça. Entretanto, para que a inclusão da aveia inteira em substituição ao 
milho seja viável é recomendada à observância do preço e do efeito do nível de inclusão.

\section{Conclusões}

A inclusão de aveia preta grão inteiro em substituição ao milho grão inteiro em até $30 \%$ da ração, não altera os índices de desempenho de cordeiros da raça Texel alimentados em confinamento com rações com elevada proporção de grãos. Esta inclusão de $30 \%$ é a mais indicada pois proporcionou no presente experimento a melhor margem bruta.

\section{Agradecimentos}

A Fundação Araucária e ao CNPq pelo suporte financeiro e pelas bolsas produtividade concedidas à Edson Luis de Azambuja Ribeiro, Ivone Yurika Mizubuti e Elzânia Sales Pereira.

\section{Referências}

ANDERSON, S. J.; MERRILL, J. K.; KLOPFENSTEIN, T. J. Soybean hulls as an energy supplement for the grazing ruminant. Journal of Animal Science, Champaign, v. 66, n. 11, p. 2959-2964, 1988.

BOLZAN, I. T.; SANCHEZ, L. M. B.; CARVALHO, P. A.; VELHO, J. P.; LIMA, L. D.; MORAES, J.; CADORIN JUNIOR, R. L. Consumo e digestibilidade em ovinos alimentados com dietas contendo grão de milho moído, inteiro ou tratado com uréia, com três níveis de concentrado. Ciência Rural, Santa Maria, v. 37, n. 1, p. 229-234, 2007.

BRASIL, Ministério Pecuária e Abastecimento. Instrução normativa n. 3, de 17 de Janeiro de 2000. Aprova o Regulamento técnico de métodos de insensibilização para o abate humanitário de animais de açougue. 2000. Disponível em: <http://www.forumnacional.com.br/ instr_normativa_n_03_de_17_01_2000.pdf.>. Acesso em: 20 jul. 2011.

CAÑEQUE, V.; SAÑUDO, C. Metodologia para el estúdio de la calidad de la canal y de la carne em ruminantes. INIA. Madrid, 2000. 254 p.

CARVALHO, S.; PIRES, C. C.; PERES, J. R. R.; ZEPPENFELD, C.; WEISS, A. Desempenho de cordeiros machos inteiros, machos castrados e fêmeas, alimentados em confinamento. Ciência Rural, Santa Maria, v. 29, n. 1, p. 129-133, 1999.

CERVIERI, R. C. Evolução do manejo nutricional nos confinamentos brasileiros: importância da utilização de subprodutos da agroindústria em dietas de maior inclusão de concentrado. In: SIMPÓSIO INTERNACIONAL DE NUTRIÇÃO DE RUMINANTES - RECENTES AVANÇOS NA NUTRIÇÃO DE BOVIOS CONFINADOS, 4., 2009, Botucatu. Anais... Botucatu: FMVZ, 2009. CD-ROM.

CROUSE, J. D.; PUSHOOM, J. R.; FIELD, R. A.; FERRELL, C. L. The effects of breed, sex, location and slaughter weight on lamb growth carcass composition and meat flavour. Journal of Animal Science, Champaign, v. 53, n. 2, p. 376-386, 1981.

CUNHA, E. A.; BUENO, M. S.; SANTOS, L. E.; RODA, D. S.; OTSUK, I. P. Desempenho e características de carcaça de cordeiros Suffolk alimentados com diferentes volumosos. Ciência Rural, Santa Maria, v. 31, n. 4, p. 671-676, 2001.

CUNHA, M. G. G.; CARVALHO, F. F. R.; VÉRAS, A. S. C.; BATISTA, A. M. V. Desempenho e digestibilidade aparente em ovinos confinados alimentados com dietas contendo níveis crescentes de caroço de algodão integral. Revista Brasileira de Zootecnia, Viçosa, v. 37, n. 6, p. 1103-1111, 2008.

FATURI, C.; RESTLE, J.; BRONDANI, I. L.; ALVES FILHO, D. C.; ROSA, J. R. P.; KUSS, F.; MENEZES, L. F. G. Grão de aveia preta em substituição ao grão de sorgo para alimentação de novilhos na fase de terminação. Revista Brasileira de Zootecnia, Viçosa, v. 32, n. 2, p. 437-448, 2003.

FURUSHO-GARCIA， I. F.; PEREZ， J. R. O.; BONAGURIO, S.; ASSIS, R. M.; PEDREIRA, B. C.; SOUZA, X. R. Desempenho de cordeiros Santa Inês puros e cruzas Santa Inês com Texel, Ile de France e Bergamácia. Revista Brasileira de Zootecnia, Viçosa, v. 33, n. 6, p. 1591-1603, 2004.

KATSUKI, P. A. Avaliação nutricional, desempenho e qualidade da carne de bovinos alimentados com rações sem forragem, com diferentes niveis de substituição do milho inteiro por casca de soja. 2009. Tese (Doutorado em Ciência Animal) - Universidade Estadual de Londrina, Londrina.

MATHISON, G. W. Effects of processing on the utilization of grain by cattle. Animal Feed Science and Technology, Amsterdam, v. 58, n. 1-2, p. 113-125, 1996.

MERTENS, D. R. Regulation of forrage intake. In: FAHEY, G. C. (Ed.). Forage quality, evaluation, and 
utilization. Madison: American Society of Agronomy, 1994, p. 450-493.

MIZUBUTI, I. Y.; PINTO, A. P.; RAMOS, B. M. O.; PEREIRA, E. S. Métodos laboratoriais de avaliação de alimentos para animais. Londrina: EDUEL, 2009. 228 p.

MURTA, R. M.; CHAVES, M. A.; SILVA, F. V.; BUTERI, C. B.; FERNANDES, O. W. B.; SANTOS, L. X. Ganho em peso e características da carcaça de ovinos confinados alimentados com bagaço de cana hidrolisado com óxido de cálcio. Ciência Animal Brasileira, Goiânia, v. 10, n. 2, p. 438-445, 2009.

NATIONAL RESEARCH COUNCIL - NRC. Nutrient requirement of beef cattle. 7. ed. Washington: National Academy Press, 1996. 232 p.

Nutrient requirements of sheep. 7. ed. Washington: National Academy Press, 2007.

NERES, M. A.; MONTEIRO, A. L. G.; GARCIA, C. A.; COSTA, C.; ARRIGONI, M. B.; ROSA, G. J. M. Forma física da ração e pesos de abate nas características de carcaça de cordeiros em creep feeding. Revista Brasileira de Zootecnia, Viçosa, v. 34, n. 6, p. 2382-2389, 2005.

PIOLA JUNIOR, W.; RIBEIRO, E. L. A.; MIZUBUTI, I. Y.; SILVA, L. D. F.; ROCHA, M. A.; BARBOSA, M. A. A. F.; SOUZA, C. L.; PAIVA, F. H. P. Ganho de peso e características da carcaça de cordeiros recebendo diferentes níveis de energia na ração. Semina: Ciências Agrárias, Londrina, v. 30, n. 4, p. 935-944, 2009.

PORDOMINGO, A. J.; JONAS, O.; ADRA, M.; JUAN, N. A.; AZCÁRATE, M. P. Evaluación de dietas basadas en grano entero, sin fibra larga, para engorde de bovinos a corral. 2002. Disponível em: <http://www.inta.gov.ar/ ediciones/ria/31_1/001.pdf.>. Acesso em: 29 maio 2010.

RESTLE, J.; FATURI, C.; PASCOAL, L. L. Efeito da forma física da aveia preta sobre o desempenho de vacas de descarte terminadas em confinamento. In: REUNIÃO ANUAL DA SOCIEDADE BRASILEIRA DE ZOOTECNIA, 38., 2001, Piracicaba. Anais... Piracicaba: SBZ, 2001.

RODRIGUES, G. H.; SUSIN, I.; PIRES, A. V.; MENDES, C. Q.; URANO, F. S.; CASTILlO, C. J. C. Polpa Cítrica em rações para cordeiros em confinamento: características da carcaça e qualidade da carne. Revista Brasileira de Zootecnia, Viçosa, v. 37, n. 10, p. 18691875, 2008.

SAS INSTITUTE. SAS/STAT. User's guide. Cary: SAS Institute Inc., 1999.

SIQUEIRA, E. R.; SIMÕES, C. D.; FERNANDES, S. Efeito do sexo e do peso ao abate sobre a produção de carne de cordeiro, velocidade de crescimento, caracteres quantitativos da carcaça, $\mathrm{pH}$ da carne e resultado econômico. Revista Brasileira de Zootecnia, Viçosa, v. 30, n. 3, p. 844-848, 2001.

URANO, F. S.; PIRES, A. V.; SUSIN, I.; MENDES, C. Q.; RODRIGUES, C. H.; ARAUJO, R. C.; MATTOS, W. R. S. Desempenho e características da carcaça de cordeiros confinados alimentados com grãos de soja. Pesquisa Agropecuária Brasileira, Brasília, v. 41, n. 10, p. 1525-1530, 2006.

VASCONCELOS, J. T.; GALYEAN, M. L. ASAS centennial paper: contributions in the journal of animal science to understanding cattle metabolic and digestive disorders. Journal of Animal Science, Champaign, v. 86, n. 7, p. 1711-1721, 2008.

ZARPELON, T. G. Substituição do milho grão inteiro por casca de soja peletizada na alimentação de cordeiros em confinamento. 2010. Dissertação (Mestrado em Ciência Animal) - Universidade Estadual de Londrina, Londrina. 